\title{
Esoteric power, useless, useful: considerations about dreams in cognitive-behavioural therapy
}

\author{
Antonino Carcione, ${ }^{1,2}$ Marta Santonastaso, ${ }^{2}$ Francesca Sferruzza, ${ }^{2}$ Ilaria Riccardi ${ }^{1,2}$ \\ ${ }^{1}$ Third Centre of Cognitive Therapy, Rome; ${ }^{2}$ Scuola Italiana di Cognitivismo Clinico (SICC), Rome, Italy
}

\begin{abstract}
For a long time dreamwork in cognitive-behavioural therapy (CBT) was considered useless and as a technique specific to psychodynamic approaches, consequently overlooked in the treatment course. In the last twenty years, thanks to the contribution of neuroscience studies on sleep and dreams, dreams joined the attention and interest of authors belonging to the CBT field. The central feature of dreamwork in CBT is the abandonment of the exploration of latent meaning, which is instead considered in continuity with the waking life. Dreams reflect a patient's view of self, world, and future, and are subject to the same cognitive biases as the waking state. Consequently, the dreamwork can be used to get information about the patient, overcome impasses in therapy, restructure self and interpersonal schemas, and stimulate reflective functioning. Therefore, guidelines have been defined and models of well-articulated intervention in terms of process and content, replicable and teachable through specific training structured. This paper aims to provide an overview of theories regarding the use of dreams in $\mathrm{CBT}$, from a clinical perspective, from Beck to more recent proposals.
\end{abstract}

Key words: Dream; dreamwork; cognitive-behavioural therapy; schema; cognitive biases.

\section{Introduction}

It was the $60 \mathrm{~s}$, Beck was still a psychoanalyst in an era of deep crisis and transformation for psychoanalysis.

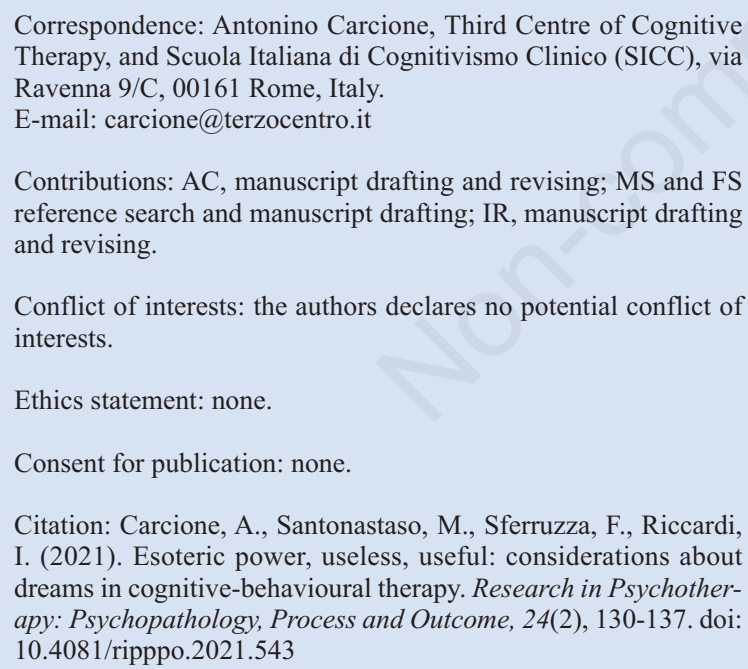

Conflict of interests: the authors declares no potential conflict of interests.

Ethics statement: none.

Consent for publication: none.

Citation: Carcione, A., Santonastaso, M., Sferruzza, F., Riccardi, I. (2021). Esoteric power, useless, useful: considerations about dreams in cognitive-behavioural therapy. Research in Psychotherapy: Psychopathology, Process and Outcome, 24(2), 130-137. doi: 10.4081/ripppo.2021.543

Received for publication: 17 March 2021.

Revision received: 22 July 2021.

Accepted for publication: 24 July 2021.

This work is licensed under a Creative Commons Attribution NonCommercial 4.0 License (CC BY-NC 4.0).

${ }^{\circ}$ Copyright: the Author(s), 2021

Licensee PAGEPress, Italy

Research in Psychotherapy:

Psychopathology, Process and Outcome 2021; 24:130-137

doi:10.4081/ripppo.2021.543
He decided to apply the method of empirical research to demonstrate that Freudian theory was truthful. He decided to study depression using dreams according to the classical principles of psychoanalysis. The thesis was that depression is associated with hostility that being inhibited is directed towards oneself, worsening the suffering. As the inhibited hostility would become unconscious he explored the dreams of two groups of patients: depressed and not depressed. The result was the opposite of expectations: the dreams of the former showed less hostility than the latter. In addition, there was a scenario in the dreams of depressed patients where they felt frustrated, devalued, denigrated. The dreams in summary described the dreamer as a losing person. In describing their dreams, the depressed patients were telling the same feelings they were experiencing in their lives (Beck, 1967). Through this anecdote, Beck describes the origin of cognitive behavioural therapy (CBT) prompting us on how, paradoxically, it was born from an analysis of dreams. Gradually, moving away from the psychoanalytic paradigm, dreams have long become something to be ignored, unscientific, used only because '...man's thirst for meaning, he has attached esoteric significances to dreams, for example, prophetic power' (Beck, 2002). The need to conform to a model of the mind that could be empirically verifiable led CBT therapists to move away from an interpretive use of dreams, considering dreamwork to be of poor clinical relevance or otherwise a topic specific to psychodynamics (Bara, 2012). Therefore, cognitivism adopted a neuropsychological position that is dreams are just an epiphenomenon of sleep, a meaningless physiological product (Hobson \& McCarley, 1977), due to the activation of brainstem areas (Bear et al., 2007) or to different brain 
areas (Domhoff, 2005) that in turns, activate areas of the cortex generating images or emotions. Therefore, dreams would lack any psychological relevance, would not provide useful information about the dreamer and, consequently, their use in psychotherapy would be useless.

Since the 2000s, however, CBT therapists have been thinking about how to profitably use dreams in psychotherapy, which are often spontaneously reported by patients themselves. First of all, they abandoned their latent meaning, typical of Freudian theories, approaching Adler's (1927) position who believed that the dream was a representation of the dreamer's world and lifestyle. Dreams are considered as a tool to reveal feelings and emotions neglected or rejected during waking life or an opportunity to solve problems through creative alternatives, free from the limits imposed by reality. In this paper we overview some of the major approaches and new trends concerning the use of dreams in CBT, using a clinical perspective.

\section{Cognitive neuroscience: the sleep-wake continuum}

In the last thirty years, thanks to experimental evidence, dreamwork has been reintegrated into the field of interest of cognitivism.

Research findings in the field of cognitive neuroscience and studies on the relation between sleep disorders, dreams, and levels of consciousness in dreaming (Schredl, Bohusch, Kahl, Mader, \& Somesan, 2000; Voss, Schermelleh-Engel, Windt, Frenzel, \& Hobson, 2013) have contributed to the knowledge of the neuroanatomical substrate and formal aspects of dreaming and its contents, specific interest of clinical psychology. De Gennaro, Marzano, Cipolli, \& Ferrara, (2012) provided data supporting the hypothesis that the encoding and recalling neurophysiological mechanisms of the episodic memory are largely shared along with different states of consciousness, shifting from sleep to waking. Therefore, the dream experience, which in turn includes the encoding and recall of fragments of stories and images, involves the same brain mechanisms entailed in encoding and recalling conscious experiences. This is also supported by Kramer \& Glucksman (2015) who point out that REM sleep, as well as general mental activity during dreaming, play an essential role in memory consolidation, information processing, and stress adaptation, as well as emotion regulation and learning (Eiser, 2005). It seems that the memories present in dreams promote learning, and consolidating the memory, through the reactivation of some perceptual elements present in the original situation (Siegel, 2001; Hobson, 2009; Velotti \& Zavattini, 2019).

The differences found in dream production during the different sleep phases, both REM and non-REM, would support the existence of a complex system of dream production that is active regardless of the specific phases. Re- cent research suggests that dreaming may have an evolutionary function involving the parietal and frontal lobes and the central region of the brainstem, i.e., areas related to the seeking/appetitive system (Panksepp, 2000; Revonsuo \& Valli, 2008) and would aim to formulate and test adaptive strategies useful during the waking life (Centonze, Cheli \& Dimaggio, 2019). According to Revonsuo (2000), the function of the dream is to simulate threatening events, to be ready to elaborate adequate coping strategies in the real world during waking life. As result dreams would be the expression of an articulated work, rather than a marginal residual phenomenon, and could be central to the understanding of mental functioning (Velotti \& Zavattini, 2019).

Consequently, if we assume that the processes involved in encoding and recall of conscious and dream experience are overlapping, it is possible to hypothesize that other aspects of conscious experience may also be present in dream experience, as well as processes of mental functioning as the emotional valence, the narrative coherence, the mechanisms of attribution, the purposes pursued (Rezzonico \& Bani 2015).

\section{The dream does not mask but represents}

In the current cognitive perspective, Freeman \& White (2002) consider the dream as the representation of an idiosyncratic dramatization of the dreamer's vision of himself and the world. Nowadays also many psychoanalysts are re-evaluating the manifest aspect of dreams as images that have validity in themselves, to be respected and possibly understood in another way (Migone, 2019). Fosshage (1983, 2002) proposes The Organizing Functions of Dreaming, - a psychoanalytic model in which dreams reveal directly the immediate problems of the dreamer, through affects, metaphors, themes, and meaning to be revealed through psychotherapy. Contrary to the classical psychoanalytic approach the author, argues that the dream does not mask anything, but simply represents. Representation is a basic function of the mind - like breathing - and it is not necessarily intentional, it occurs spontaneously and entirely subjectively, but - like breathing - can become the object of conscious attention by the person and be used as a cognitive tool and therapeutic work. Cognitivism works a lot on mental representations, consequently the dream - considered as a representation becomes an object of interest in CBT as well. Since we regard mental activity during dreaming, as well as during waking life, as a representational process, it follows based on our knowledge of vigil mental activity - that it varies concerning subjective meaning. The idea that the meaning of dreams can vary from person to person is radically different from the classical model in which it is assumed that there is always a deeper latent meaning that can be identified by referring to a universal symbolism of interpretation (Fosshage, 2002), with an important hidden 
meaning to be found. The charm of dream symbolism should be avoided and then in therapy, a dream should be understood by linking it to events of the patient's life and his waking experiences (Freeman \& White, 2002).

\section{A different perspective in cognitive-behavioural therapy: the debate between the constructivism and rationalism positions}

In the ' 80 s and ' 90 s some authors referring to Guidano (Guidano, 1987; 1991; Mahoney, 1995), adopting a position of radical constructivism, criticized the traditional CBT approach, Beck's one, in particular, considering it too rationalistic and not very interested in emotional experience. In this perspective, the use of dreams in therapy is another way to differentiate this approach from the standard CBT. In this debate, the constructivism perspective focuses on the narrative aspect and on the construction of the meaning of the dream that therapist and patient build together (Rezzonico \& Bani, 2015), with the overall goal of using dreams to bring out some personal meanings to achieve a greater awareness from the patient (Guidano, 1991). There would be no defined and scheduled moments in which to use the dream during therapy, but it is a topic that can be raised on any occasion, by the therapist and the patient indiscriminately. The dream is investigated in its metaphorical and specific dimensions according to the dreamer approach (Rosner, Lyddon \& Freeman, 2004). Also, Liotti (2004) proposes to consider the dream as a particular type of metaphorical thinking whose function is to consolidate and establish memories of events and self-knowledge.

On the other hand, CBT, whose general focus is to find cognitive biases, proposes that the same biases possibly could be shared between dreaming and waking. According to this approach, dreams can be used to facilitate a cognitive restructuring, focusing on explicit meanings rather than on symbolic contents. In this perspective, dreams are used only if reported by the patient, and only if the therapeutic process is at an impasse. Beck moved dreamwork from the latent level of analysis to the manifest level and from a motivational view to a cognitive view (Rosner, 1997) defining the dream as 'a visual phenomenon that occurs during sleep' (Beck, 2002). Considering the cognitive model of dreams, he argued that clinical practice demonstrated the presence of a link between the dream and the dreamer. To support this statement he conducted systematic, controlled studies on depressed patients. It emerged that the recurrent themes during waking life were also characteristic of dream activity such as, for example, that of failure (Beck, 1967). Beck also reports an interesting study on prisoners and found a significant presence of contents within the dreams related to the crime committed (Beck, 2002). He believed that dreams reflected the cognitive model of the specific patient and thanks to them it was possible to find mal- adaptive patterns and cognitive biases. Accordingly, dreams became a useful tool for the cognitive restructuring process. Beck argued that the individual's conceptualizations of various situations during the waking life, and the perception of oneself, of the world and the future, influences the content of dreams and vice versa; therefore, conceptualizations and representations made during the dreaming, based on more primitive schemes, affect the emotions and behaviours during the waking life.

Recently, several authors focused their studies on this topic; among them, Barrett (2002) supports Beck's idea that dreaming conceptualization has a strong influence on wakefulness' emotions and behaviours.

Findings from several studies, highlight that dreamwork is a new method to reach cognitive distortions also present during wakefulness. Freeman and White (2004) define the dream as an idiosyncratic and dramatic view that the individual has of him/herself and the world. According to the authors, a focus on themes and images of the dream, concerning the specific person is needed rather than on general symbolic representations. Thus, they describe some guidelines on the cognitive interpretation of dreams: pay attention to the understanding of the dream in thematic rather than symbolic terms; the thematic content is idiosyncratic to the dreamer and must be understood within context of his/her waking life; the affective responses to the dream image can be seen as similar to the patient's emotional responses in waking life; the dream content and imagery fall under the same cognitive restructuring methods as automatic thoughts; the dream may reflect the patient's schema. Young, Klosko, \& Weishaar (2003) and Dimaggio (2004) emphasize the possibility of using dreams, particularly recurrent dreams, to highlight patients' self and interpersonal schemas. In schema therapy telling a dream can be a starting point for the use of experiential methods such as imagery to promote change in the dysfunctional schema. Authors (Dimaggio, 2004; Centonze et al., 2019) suggest considering the dream as an operation of active, online writing and rewriting of mental scenes. Dreams are expressions of schemas; the recurrent ones, in particular, are the most pervasive so dreams can be the way to access otherwise inaccessible or dissociated parts of the Self. The dream then can be a narrative plot for using imagery through rescripting technique.

\section{Dreamwork in cognitive-behavioural therapy}

Two reviews of the empirical studies (Eudell-Simmons \& Hilsenroth, 2005; Pesant \& Zadra, 2004) have shown how the use of dreams can improve four different areas: facilitating the therapeutic process, providing self-knowledge for the patient, providing clinically relevant information for the therapist and providing an indication of clinically significant change in the patient within therapy.

An interesting perspective is Skrzypińska and 
Szmigielska's (2018) model who proposes an interesting integration of dreamwork within the classic three phases of the CBT process, namely: i) clinical diagnosis and case formulation; ii) achievement of therapeutic goals; and iii) evaluation and maintenance of the results achieved. Clara Hill's cognitive-experimental model and Jacques Montangero's recent DMR model also do not differ substantially from the former. Hill (1996), integrates different theoretical orientations in his cognitive-experimental models, such as existential-phenomenological approaches, psychoanalysis, cognitivism, behaviourism, and gestalt. Although this framework does not allow it to be named, properly, as a model of cognitive-behavioural therapy, its integrative characteristic, is adherent to Beck's concept, of CBT as an integrated approach when needed (Skrzypińska \& Szmigielska, 2018). Hill and Rochlen (2002) set out in clear detail the model and its use in clinical practice. The authors depart from symbolism, stating that the purpose of dreamwork in therapy is to access the patient's cognitive schemas and make them functional in finding solutions to problems in waking life. In achieving this goal, the therapist's role consists of being a facilitator rather than the holder of the dream meaning, since it is the patient who has the key to achieving this awareness. The structure of the cognitive-experimental model is divided into three phases, aimed at changing dysfunctional patterns; these are exploration, insight, and action stages.

\section{Dream as a tool to facilitate the therapeutic process}

Working with dreams can facilitate the therapeutic process by increasing the patient's level of engagement in the therapeutic relationship. For some constructivist authors, patients who frequently report dreams in therapy may represent a critical issue for a therapist who views them as mere background noise or who lacks adequate training in their use. Accordingly, there is a risk to ignore both something assessable and useful in therapeutic work, and something hurting the therapeutic relationship. The negation of examining dream material may be perceived as rejection or invalidation, given the value that the patient ascribes to the dream (Rezzonico \& Bani, 2015). Undoubtedly, building a good therapeutic relationship is a crucial factor for a good outcome of psychotherapy (Horvath, 2013; Safran \& Segal, 1990; Wampold, 2015) and the relationship must perform its function by fostering collaboration to formulate and solve together a psychological problem (Saliani, 2021). Therefore the use of dreams during psychotherapy can be a part of the negotiation between patient and therapist to build an agreement on the objective and tasks necessary to establish a good alliance (Bordin, 1979). In our opinion, it is important to clarify the methods and techniques of treatment, and therefore how dreams will be used in therapy considering the use of dreams on the same level as any technique that a therapist may or may not decide to use de- pending on his/her training and competence to reduce risks of rupture.

\section{Use of dreams to provide clinical information to the therapist and to facilitate self-knowledge}

As pointed out by Skrzypińska and Szmigielska (2018), the diagnostic and case-formulation stage represent the foundation for the formulation of the treatment plan in CBT. During this phase, it might be useful to include, especially if the patient does it spontaneously, dreamwork as a technique that facilitates the process of acquiring information about the patient. The content of dreams, as for automatic thoughts, can be recorded within the homework, and then be part of the therapeutic work during the session, just as it happens with the $\mathrm{ABC}$ technique, to look for a recurrence of life themes, automatic thoughts, and associated emotional states. Specific homework for collecting dream material may be the Dream Log (DL) (Alford and Beck, 1997) and the Dream Analysis Record (DAR) (Alford and Norcross, 1991). The DL invites patients to keep a notebook, a diary, on their bedside table and record everything they remember about the dreams, even a fragment, immediately upon awakening, writing down emotions, automatic thoughts, and reflections associated with the dream. The DAR is structured as a five-column table: in the first column one enters the date on which the dream took place; in the second column a summary of the dream, its salient parts; in the third column one writes down the emotional reactions, evaluating their intensity; the fourth column requires the person to restructure the contents, the course and the representations of the dream, finally in the fifth column the re-evaluation of the degree of emotion associated with the dream image can be noted. During the sessions, the patient and therapist work together on the material collected, which may also emerge during the session directly.

Case formulation ends with an agreement about the goals of therapy. One of the classic CBT methods of goalsetting is the technique known as cognitive restructuring, and dreamwork can be a facilitator of this process. Taking up the continuity hypothesis formulated by Hall and Nordby (1972) and the cognitive specificity hypothesis, which is a component of Beck's (2002) cognitive theory, reformulation of dream content takes on the same structure as working with automatic thoughts.

\section{Use of the dream as an indicator of change}

To assess the results achieved in the last stage of CBT, the changes attained are reviewed, and if dreamwork has been used, the exploration of changes related to dreaming content - and associated emotional and cognitive responses - can be considered as a measure of changes achieved in the waking life. Moreover, the same changes 
that occur in dream activity can be generalized and applied to problems present during waking life (Skrzypińska and Szmigielska, 2018).

Caroppo, Dimaggio, Popolo, Salvatore, \& Ruggeri (1997) examining a series of dreams from a patient undergoing psychotherapy, described significant changes in dream content between the first 18 and the last 18 dreams which reflected an improvement in the patient's ability to cope with problems and conflicts. Dimaggio, Popolo, Serio, \& Ruggeri (1997) also found a change in emotional tone throughout psychotherapy, with an increase in pleasant versus unpleasant emotions.

\section{The Description, Memory Sources, and Reformulation model}

Jacques Montangero (2009) highlights how dreaming includes several cognitive processes such as the recall of memories from autobiographical memory their representation in visual images, the organization of the dream scenario and its unfolding. According to the author, humans are endowed with semiotics, i.e., representational function (Piaget \& Inhelder, 1969), which allow them to produce representations both during waking life and during dreaming.

The dream often presents discontinuity or an interrupted narrative because the mind works effortlessly as the representations produced to have any rules of reality. Since these peculiarities of the dream content, the patient needs to enact a metaphorical conversion, which in turn enable that important personal contents emerge and as Beck argued, providing further information about how the patient perceives himself and the world (Beck, 2002).

Montangero proposes a structured and systematic model, the DMR (Description, Memory Sources, and Reformulation), based on the patient's insight and interpretative abilities, rather than the therapist's ones. The cues provided by the patient form the basis of his/her dream interpretation. The procedure includes three steps, after which the patient will be asked for an interpretation:

i) Description, in which the therapist asks the patient to describe the dream, dwelling on every detail that appeared in the dream scenario, the sequence of events thought or emotions felt. Techniques of cognitive-behavioural therapy as $\mathrm{ABC}$ can also be used.

The therapist provides the following instructions: ' $I$ have an idea of your dream thanks to your report, but it is still a vague and incomplete idea. In order to work fruitfully on this dream, we must take into account everything you saw, heard, or felt during the dream experience. Please describe the dream again to me, specifying everything that you visualized or that was present without being visualized and indicating what was clear or blurred or indistinct. I am also interested in the sequence of events and would like to distinguish what was simultaneous or successive. Finally, if you felt an emotion during the dream, don't forget to describe it.' (Montangero, 2009, p.245)

The patient should describe what he/she visualized, felt, or thought during each dream event, detailing the setting, action or state, characters, and objects. The therapist notes each episode in chronological order as reported by the subject, each change of scenario or situation the patient described.

ii) Memory Sources. Based on the assumption that the dream partly takes its cue from autobiographical memory, at this stage it is necessary to recognize which memories have spilled over into the dream. In case this link is not so clear, it is also possible to focus on a detail of the image that is being examined and ask if there is a recall of the mnestic trace. The therapist must always ask the patient the meaning of that event, image, or action and the degree of pleasantness linked to it.

iii) Reformulation. This is the ultimate stage, in which the dream is asked to be presented again, not as a specific and concrete event, but by reconnecting the broader and more general meanings, found in the second stage, that could later be applied to the dreamer's aspirations or concerns. According to the author 'an idea, character, or action can be represented in a dream by anything that belongs to the same superordinate category. As a consequence, the meaning of some content of a dream may sometimes lie not in the specific dream element, but in the encompassing category it belongs to' (Montangero, 2009, p.247). The dream interpretation can occur immediately at the end of the reformulation or even during the latter.

Freeman and White (2002) point out that it is possible to use the procedure in abbreviated form, focusing only on the main aspects of the dream, especially when it is very long.

Montangero believes that every dream can be addressed in therapy, he suggests the use of the $A B C$ to stimulate the subject to understand the existing relationship among events, thoughts, emotions, and behaviors, encouraging the emergence of new personal contents. Dreams allow to: recognize cognitive biases, patient's dysfunctional patterns, facilitate cognitive restructuring, observe patient's improvements and abilities. About cognitive biases, it is easier to detect them into dreams than in waking life, since dream representations are often dramatized and exaggerated. For the same reason, dreamwork can facilitate cognitive restructuring, since - after reformulation - the patient has a clearer view of the meaning of the dream and this can lead to understanding how, during waking life, how certain situations or events are conceived can be counterproductive and inappropriate. Moreover, about the identification of the patient's dysfunctional patterns, or beliefs leading to negative thoughts, the dream may show their resulting behaviour, possibly to be treated in a CBT setting. The reformulation of the dream can also show a patient's ef- 
ficient behaviour or attitude, emerging from improvements got through the therapeutic process that the therapist will highlight.

\section{Dreaming and increasing reflective processes}

There are no methods expressly directed at eliciting metacognition (Carcione et al., 2010. Metacognition Assessment Scale (MAS) V.4.0-Manual, Unpublished manuscript; Carcione, Nicolò, \& Semerari, 2021), other than those suggested by Centonze et al. (2019) who directly refer to Metacognitive Interpersonal Therapy (Dimaggio, Montano, Popolo, \& Salvatore, 2015; Carcione et al., 2021). In any case, various aspects of dreamwork as described in this paper could prompt an increase in metacognitive functioning. Montangero's DMR itself, by soliciting autobiographical memories and narrative plots may be useful in increasing reflective skills; particularly they could be solicited by the therapist when therapeutic work is at an impasse. Dreaming could also be a way to allow the patient to approach particularly painful contents gradually while maintaining a certain degree of distance and protection.

Bara (2012) proposes emotion-centred work, emphasizing the importance of the therapeutic relationship. In the intervention suggested, the plot of the dream takes a secondary role, since the therapeutic aim is focused on the conscious recall, as far as possible, of the oneiric emotional state. Telling the dream to the psychotherapist in a co-empathic relationship would increase the awareness of the patient's cognitive, emotional, and somatic processes that take shape in the here and now of the story.

Since dreams are characterized by an important emotional charge, using them in psychotherapy can be particularly advantageous for patients who have difficulty in accessing affective states and regulating emotions; hence it provides a further opportunity to integrate, during the self-monitoring process, the emotional charge sometimes elusive in the waking life.

Furthermore, we stress that to usefully work on dreams patient needs to properly differentiate between fantasy and reality, to avoid considering dreams as happened during the waking state.

\section{Conclusions}

Although the authors of this paper do not generally use dreamwork in therapy, they considered it suitable and useful to propose an overview on this topic, from a clinical point of view, considering dreamwork a possible technique to be used in treatment, in an integrated perspective proper to CBT. This perspective can be useful to meet patients' spontaneous attitudes for narrative patterns that encourage reflection on mental states and increase metacognition, especially for those who are emotionally inhibited or experience an impasse in therapy. Frequently, the different theoretical orientations have emphasized the divergent viewpoints as opposite to convergent on the dream issue. Over the last years, several authors are focusing on convergence, proposing, for example, to use studies on cybernetic information networks to create a general framework to capture common features within research and dreamwork, to overcome the theoretical debates (Vedfelt, 2020).

What fundamentally emerges from the proposed literature and models on a dream is that the therapist should avoid the pitfall of universal symbolism concerning dreams. Whereas, the therapist must work to understand and analyse dream content, by identifying associations with the patient's life and with his/her awareness of his/her own experiences and functioning. Thus, the dream should be read as an expression of the Self in continuity with waking life. The use of dreams in CBT enables the person to let personal meanings emerge and reach a higher level of self-knowledge and awareness of their own psychological functioning; through the co-construction of meanings between patient and therapist, it can facilitate changes in real life. The psychotherapeutic work takes place through telling images, thoughts, and emotions related to the dream; then by modifying and restructuring the content of the dream it facilitates change, the emergence of functional coping strategies, and the disappearance of symptoms. The dreamwork can be compared to functional analysis work on the contents and processes occurring during waking life.

It should certainly be considered that therapists' and patients' views on dreams can influence how they are used during psychotherapy (Eudell-Simmons \& Hilsenroth, 2005). For example, therapists who solicit dreams will encounter many more in therapy than those who do not, and patients who remember dreams, have more vivid dreams (Hill, Diemer, Hess, Hillyer, \& Seeman, 1993) or who have more positive attitudes toward dreams (Cartwright, 1977; Hill, Diemer, \& Heaton, 1997), will tend to tell them more frequently into therapy than those who rarely remember them.

In any case, studies conducted did not find dreamwork to be superior to other techniques used in therapy; treatments using dream interpretation have overall been found to be effective or not damaging (Diemer, Lobell, Vivino, \& Hill, 1996; Hill, 1996; Hill \& Knox, 2010).

To the best of our knowledge, no experiments have yet been conducted on the impact of introducing dream analysis into the mainstream of cognitive-behavioural therapy. Such experiments will only be possible when sufficient numbers of patients can be treated by CBT therapists using a similar method of dream analysis. To further explore this topic, it would be useful to collect empirical data from those who routinely use dreamwork in the course of therapy, particularly if the patient shows interest, thus expanding the pool of empirical evidence. 


\section{References}

Adler, A. (1927). The practice and theory of individual psychology. New York: Harcourt, Brace.

Alford, B. A., \& Norcross, J. C. (1991). Cognitive therapy as integrative therapy. Journal of Psychotherapy Integration, 1(3), 175-190. doi: 10.1037/h0101234.

Alford, B. A., Beck, A. T., \& Jones Jr, J. V. (1997). The integrative power of cognitive therapy. New York, NY: Guilford Press.

Bara, B.G. (2012). Dimmi come sogni. Interpretazione emotiva dell'esperienza onirica. Milano: Mondadori.

Barrett, D. (2002). The 'royal road' becomes a shrewd shortcut: The use of dreams in focused treatment. Journal of Cognitive Psychotherapy, 16(1), 55-63. doi: 10.1891/jcop.16. 1.55.63701.

Bear, M.F., Connors, B.W., \& Paradiso M.A. (2020). Neuroscience, exploring the Brain. Philadelphia, PA: Lippincott Williams \& Wilkins.

Beck, A. T. (1967). Depression. Clinical, Experimental and Theoretical Aspects. New York, NY: Hoeber Inc.

Beck, A. T. (2002). Cognitive patterns in dreams and daydreams. Journal of Cognitive Psychotherapy, 16(1), 23. doi: 10.1891/jcop.16.1.23.63703.

Bordin, E. S. (1979). The generalizability of the psychoanalytic concept of the working alliance. Psychotherapy: Theory, research \& practice, 16(3), 252-260. doi: 10.1037/h0085885.

Carcione, A., Nicolò, G., \& Semerari, A. (2021). Complex Cases of Personality Disorders: Metacognitive Interpersonal Therapy. New York, NY: Springer. [In press].

Caroppo, E., Dimaggio, G. G., Popolo, R., Salvatore, G., \& Ruggeri, G. (1997). Recurrent oneiric themes: A clinical research on dream evaluation during psychotherapy. New trends in experimental and clinical psychiatry, 13, 275-278.

Cartwright, R. (1977). Night life: Explorations in dreaming. Englewood Cliffs, NJ: Prentice-Hall.

Centonze, A., Cheli, S., \& Dimaggio, G. (2019). Il ruolo del sogno nel promuovere un cambiamento (cosciente) degli schemi interpersonali. Giornale italiano di psicologia, 46(3), 491-496. doi: $10.1421 / 94511$.

De Gennaro, L., Marzano, C., Cipolli, C., \& Ferrara, M. (2012). How we remember the stuff that dreams are made of: neurobiological approaches to the brain mechanisms of dream recall. Behavioural brain research, 226(2), 592-596. doi: 10.1016/j.bbr.2011.10.017

Diemer, R. A., Lobell, L. K., Vivino, B. L., \& Hill, C. E. (1996). Comparison of dream interpretation, event, interpretation, and unstructured sessions in brief therapy. Journal of counseling psychology, 43(1), 99-112. doi: 10.1037/00220167.43.1.99.

Dimaggio, G.G., Popolo, R., Serio, A.V., \& Ruggeri, G. (1997). Dream emotional experience changes and psychotherapeutic process: An experimental contribu- tion. New Trends in Experimental and Clinical Psychiatry, 8(4), 271-273.

Dimaggio, G. (2004). La riscrittura della mappa del mondo. In G. Rezzonico, D. Liccione (Eds.), Sogni e psicoterapia. L'uso del materiale onirico in psicoterapia cognitiva (pp. 267-276). Torino: Bollati Boringhieri.

Dimaggio, G., Montano, A., Popolo, R., \& Salvatore, S. (2015). Metacognitive Interpersonal Therapy for Personality Disorder: A Treatment Manual. New York, NY: Routledge. doi: 10.4324/9781315744124.

Domhoff, G. W. (2005). Refocusing the neurocognitive approach to dreams: a critique of the Hobson versus Solms debate. Dreaming, 15(1), 3. doi: 10.1037/1053-0797.15.1.3.

Eiser, A. S. (2005). Physiology and psychology of dreams. Seminars in neurology, 25(1), 97-105.

Eudell-Simmons, E. M., \& Hilsenroth, M. J. (2005). A review of empirical research supporting four conceptual uses of dreams in psychotherapy. Clinical Psychology \& Psychotherapy: An International Journal of Theory \& Practice, 12(4), 255-269. doi: 10.1002/cpp.445.

Freeman, A., \& White, B. (2002). Dreams and the dream image: Using dreams in cognitive therapy. Journal of Cognitive Psychotherapy, 16(1), 39-54. doi: 10.1891/jcop.16.1.39.63706.

Fosshage, J. L. (1983). The psychological function of dreams: A revised psychoanalytic perspective. Psychoanalysis and Contemporary Thought, 6(4), 641-669.

Fosshage, J. L. (2002). A relational self-psychological perspective. Journal of Analytical Psychology, 47(1), 67-82. doi: 10.1111/1465-5922.00289.

Guidano, V.F. (1987). Complexity of the Self. New York, NY: Guilford (Tr. It.: La complessità del Sé. Torino: Bollati Boringhieri, 1988).

Guidano, V. (1991). The Self in process:Toward a post-rationalist cognitive therapy. New York, NY: Guilford (Tr. It.: Il Sé nel suo divenire. Torino: Bollati Boringhieri, 1992).

Hall, C.S., \& Nordby, V.J. (1972) The Individual and His Dreams. New York, NY: New American Library.

Hill, C. E., Diemer, R., Hess, S., Hillyer, A., \& Seeman, R. (1993). Are the effects of dream interpretation on session quality, insight, and emotions due to the dream itself, to projection, or to the interpretation process? Dreaming, 3(4), 269-280. doi: $10.1037 / \mathrm{h} 0094385$.

Hill, C. E. (1996). Working with dreams in psychotherapy. New York, NY: Guilford Press.

Hill, C. E., Diemer, R. A., \& Heaton, K. J. (1997). Dream interpretation sessions: Who volunteers, who benefits, and what volunteer clients view as most and least helpful. Journal of Counseling Psychology, 44(1), 53-62. doi: 10.1037/00220167.44.1.53.

Hill, C.E., \& Rochlen, A. B. (2002). The Hill cognitive-experiential model of dream interpretation. Journal of Cognitive Psychotherapy, 16(1), 75-89. doi: 10.1891/jcop.16.1.75.63705.

Hill, C.E., \& Knox, S. (2010). The use of dreams in modern psychotherapy. International review of neurobiology, 92, 291317. doi: 10.1016/S0074-7742(10)92013-8.

Hobson J.A., \& McCarley R.W. (1977). The brain as a dream state generator: An activation-synthesis hypothesis of the dream process. American Journal of Psychiatry, 134(12), 13351348. doi: 10.1176/ajp.134.12.1335.

Hobson, J.A. (2009). REM sleep and dreaming: towards a theory of protoconsciousness. Nature Reviews Neuroscience, 10(11), 803-813. doi: 10.1038/nrn2716.

Horvath, A.O. (2013). You can't step into the same river twice, but you can stub your toes on the same rock: Psychotherapy outcome from a 50-year perspective. Psychoterapy, 50(1), 2532. doi: 10.1037/a0030899.

Kramer, M., \& Glucksman, M. L. (Eds.). (2015). Dream research: Contributions to clinical practice. New York, NY: Routledge.

Liotti, G. (2004). L'uso del materiale onirico in psicoterapia cognitiva. In Rezzonico G., Liccione D. (Eds.), Sogni e psicoterapia. L'uso del materiale onirico in psicoterapia cognitiva (pp. 240-251). Torino: Bollati Boringhieri.

Mahoney, M. J. (1995). Cognitive and constructive psychotherapies. Theory, research, and practice. New York, NY, Wash- 
ington, DC: Springer Publishing Company, Inc. and American Psychological Association.

Migone, P. (2019). La psicoanalisi e il sogno. Giornale italiano di psicologia, 46(3), 561-566. doi: 10.1421/94523.

Montangero, J. (2009). Using dreams in cognitive behavioural psychotherapy: Theory, method, and examples. Dreaming, 19(4), 239-254. doi: 10.1037/a0017613.

Panksepp, J. (2000). 'The dream of reason creates monsters'... especially when we neglect the role of emotions in REM-states. Behavioural and Brain Sciences, 23(6), 988-990. doi: 10.1017/S0140525X00764028.

Pesant, N., \& Zadra, A. (2004). Working with dreams in therapy: What do we know and what should we do? Clinical psychology review, 24(5), 489-512. doi: 10.1016/j.cpr.2004.05.002.

Piaget, J., \& Inhelder, B. (1969). The psychology of the child. New York, NY: Basic Books.

Revonsuo, A. (2000). The reinterpretation of dreams: an evolutionary hypothesis of the function of dreaming. Behavioural and Brain Science, 23, 6, 877-901.

Revonsuo, A., \& Valli, K. (2008). How to test the threat-simulation theory. Consciousness and Cognition, 17(4), 1292-1296. doi: 10.1016/j.concog.2008.01.007.

Rezzonico, G., \& Bani, M. (2015). L'uso dei sogni in psicoterapia cognitivo-comportamentale: a che punto siamo? Psicoterapia Cognitiva e Comportamentale, 21(3), 285-301.

Rosner, R. I. (1997). Cognitive therapy, constructivism, and dreams: A critical review. Journal of Constructivist Psychology, 10(3), 249-273. doi: 10.1080/10720539708404625.

Rosner, R. I., Lyddon, W. J., \& Freeman, A. (2004). Cognitive therapy and dreams: An introduction. Cognitive therapy and dreams, 3-8.

Safran, J. D., \& Segal, Z. V. (1990). Interpersonal process in cognitive therapy. New York, NY: Basic Books.
Saliani, A.M. (2021). La relazione terapeutica: tra psicoterapia cognitiva e control-mastery theory. In Perdighe, C., \& Gragnani, A. (Eds.), Psicoterapia cognitiva. Comprendere e curare $i$ disturbi emotivi, Milano: Raffaello Cortina.

Schredl, M., Bohusch, C., Kahl, J., Mader, A., \& Somesan, A. (2000). The use of dreams in psychotherapy: A survey of psychotherapists in private practice. The Journal of psychotherapy practice and research, $9(2), 81$.

Siegel, J. M. (2001). The REM sleep-memory consolidation hypothesis. Science, 294(5544), 1058-1063. doi: 10.1126/science. 1063049 .

Skrzypińska, D., \& Szmigielska, B. (2018). Dreams in cognitivebehavioural therapy. Cognitive behavioural therapy and clinical applications, 6, 97-115. doi: 10.5772/intechopen.70893.

Vedfelt, O. (2020). Integration versus conflict between schools of dream theory and dreamwork: integrating the psychological core qualities of dreams with the contemporary knowledge of the dreaming brain. Journal of Analytical Psychology, 65(1), 88-115. doi: 10.1111/1468-5922.12574.

Velotti, P., \& Zavattini, G. C. (2019). È ancora attuale l'uso del sogno nella pratica clinica? Giornale italiano di psicologia, 46(3), 433-462. doi: 10.1421/94505.

Voss, U., Schermelleh-Engel, K., Windt, J., Frenzel, C., \& Hobson, A. (2013). Measuring consciousness in dreams: the lucidity and consciousness in dreams scale. Consciousness and Cognition, 22(1), 8-21. doi: 10.1016/j.concog.2012. 11.001 .

Wampold, B. E. (2015). How important are the common factors in psychoterapy? An up-date. World Psychiatry, 14(3): 2707. doi: $10.1002 /$ wps.20238.

Young, J. E., Klosko, J. S., \& Weishaar, M. E. (2003). Schema Therapy: A Practitioner's Guide. New York, NY: Guilford Press. 